\title{
Hymenopteran parasitoids reared from preimaginal stages of lepidopteran feeding on highbush blueberry (Vaccinium corymbosum L.)
}

\author{
Parazytoidy z rzędu Hymenoptera wyhodowane \\ ze stadiów preimaginalnych motyli żerujących \\ na borówce wysokiej (Vaccinium corymbosum L.)
}

\author{
Małgorzata Janiuk, Magdalena Gantner
}

\begin{abstract}
Summary
Studies on the species composition of parasitoids were conducted in 2003-2006 on three highbush blueberry plantations near Lublin. In total 1.547 caterpillars from Geometridae, Lymantriidae, Noctuidae and Tortricidae moth families were collected from observed bushes. The number of moth caterpillars and their parasitization varied depending on the year and the locality. An average parasitization was $6.85 \%$. As a result of laboratory rearing, twelve species belonging to Chalcidoidea and Ichneumonoidea superfamilies of Hymenoptera-Parasitica were obtained. The most numerous was the Ichneumonidae familyand Phytodietus segmentator, Cotesia ater and Itoplectis maculator were the most effective parasitiods.
\end{abstract}

Key words: hymenopteran parasitoids, polyphagous caterpillars, highbush blueberry

\begin{abstract}
Streszczenie
Badania nad składem gatunkowym parazytoidów prowadzono w latach 2003-2006 na trzech plantacjach borówki wysokiej w okolicach Lublina. Na krzewach borówki zebrano 1547 gąsienic motyli z rodzin: miernikowcowatych (Geometridae), brudnicowatych (Lymantriidae), sówkowatych (Noctuidae) i zwójkowatych (Tortricidae). Liczebność larw motyli i ich spasożytowanie były zróżnicowane w zależności od roku i stanowiska badań. Średnio spasożytowanie gąsienic wyniosło 6,85\%. W wyniku przeprowadzonej hodowli uzyskano osobniki dorosłe Hymenoptera-Parasitica, należące do dwunastu gatunków z nadrodzin: Chalcidoidea i Ichneumonoidea. Najliczniej reprezentowana była rodzina Ichneumonidae, a najefektywniejszymi parazytoidami były Phytodietus segmentator, Cotesia ater i Itoplectis maculator.
\end{abstract}

Słowa kluczowe: parazytoidy, Hymenoptera, polifagiczne gąsienice, borówka wysoka

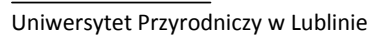

Katedra Entomologii

Leszczyńskiego 7, 20-069 Lublin

malgorzata.janiuk@up.lublin.pl; magda.gantner@up.lublin.pl
} 


\section{Wstęp / Introduction}

Motyle polifagiczne, a wśród nich gatunki należące do rodziny zwójkowatych, to szkodniki powszechnie występujące na roślinach sadowniczych (Płuciennik i Olszak 2010a; Płuciennik 2013). W celu określenia potrzeby ich zwalczania, w trakcie całego sezonu wegetacyjnego, powinna być prowadzona systematyczna lustracja. W czasie prowadzonego monitoringu należy zwracać szczególną uwagę na obecność i liczebność fauny pożytecznej, która jest bardzo ważnym elementem walki ze szkodnikami (Łabanowska i Maciesiak 2013). Jak wynika z badań przeprowadzonych przez Janiuk i wsp. (2011) borówka wysoka (Vaccinium corymbosum L.), pomimo dość krótkiego okresu uprawy w Polsce, jest chętnie zasiedlana przez polifagiczne gąsienice motyli, uszkadzające liście.

Celem pracy było poznanie składu gatunkowego i efektywności parazytoidów ograniczających liczebność gąsienic żerujących na krzewach borówki wysokiej.

\section{Materiały i metody / Materials and methods}

Badania nad składem gatunkowym parazytoidów prowadzono w latach 2003-2006 na trzech plantacjach borówki wysokiej w okolicach Lublina: w Palikijach, Niemcach i Osmolicach. Na każdej plantacji przeglądano po 30 krzewów metodą „na upatrzonego” w poszukiwaniu larw motyli. Obserwacje prowadzono w odstępach około 10-dniowych przez cały sezon wegetacyjny. Zebrane gąsienice hodowano w celu uzyskania postaci dorosłych motyli i parazytoidów. Wyhodowane osobniki pasożytniczych błonkówek zatruwano i oznaczano do gatunku lub rodzaju.

\section{Wyniki i dyskusja / Results and discussion}

W wyniku przeprowadzonych badań stwierdzono obecność 1547 gąsienic motyli należących do czterech rodzin: miernikowcowatych (Geometridae), brudnicowatych (Lymantriidae), sówkowatych (Noctuidae) i zwójkowatych (Tortricidae). Najliczniej reprezentowana była rodzina zwójkowatych, z dominującą zwójką różóweczką (Archips rosana L.). W trakcie hodowli 101 gąsienic okazało się porażonych przez parazytoidy należące do rzędu Hymenoptera. Liczebność larw motyli i ich spasożytowanie były zróżnicowane w zależności od roku i stanowiska badań. Najwięcej gąsienic zebrano w roku 2003 (901 osobników), a najmniej w roku 2005 (81 osobników). Jak wynika z badań przeprowadzonych przez Płuciennik (2013) warunki pogodowe stanowią jeden z głównych czynników determinujących występowanie gąsienic, a w szczególności zwójkówek.

Spasożytowanie larw motyli w latach badań wahało się od $1,72 \%$ w roku 2004 do 10,13\% w roku 2006. Najwięcej gąsienic żerowało na krzewach borówki wysokiej na plantacji w Palikijach, a najwyższy procent spasożytowanych gassienic stwierdzono na plantacji w Osmolicach (tab. 1). Ogółem w okresie badań spasożytowanie gąsienic żerujących na krzewach borówki wysokiej wyniosło $6,85 \%$. Spasożytowanie zwójek żerujących na porzeczce czarnej odnotowane przez Piekarską-Boniecką i Wilkaniec (1996) oraz Tiana i Piekarską-Boniecką (1998) było znacznie wyższe i wahało się od 14,1 do $47,8 \%$. Spasożytowanie zwójek żerujących w sadach jabłoniowych wyniosło średnio 8,6\% (Płuciennik i Olszak 2010b).

W wyniku przeprowadzonej hodowli z 80 gąsienic uzyskano osobniki dorosłe Hymenoptera-Parasitica, należące do dwunastu gatunków $\mathrm{z}$ czterech rodzin i dwóch nadrodzin: Chalcidoidea i Ichneumonoidea (tab. 2). Najliczniej reprezentowana była rodzina Ichneumonidae, do której zaliczono osiem gatunków. Rodziny Eulophidae i Pteromalidae były reprezentowane przez pojedyncze gatunki. Najliczniejszym parazytoidem okazał się gąsienicznik Phytodietus segmentator, który spasożytował 32 gąsienice. Cotesia ater z rodziny Braconidae i Itoplectis maculator z rodziny Ichneumonidae spasożytowały odpowiednio 17 i 12 gąsienic. Badania większości autorów wskazują, że błonkówki pasożytnicze, a wśród nich rodziny Ichneumonidae, Chalcididae i Braconidae należą do najbardziej efektywnych parazytoidów larw motyli (Miczulski i Anasiewicz 1972; Piekarska 1989; Płuciennik i Olszak 2010b).

Najwięcej błonkówek pasożytniczych wyhodowano z gąsienic zebranych na plantacji borówki wysokiej w Palikijach, gdzie stwierdzono również ich największą różnorodność gatunkową (rys. 1). Z ogólnej liczby dwunastu uzyskanych w hodowli gatunków, dziesięć wystąpiło na tej plantacji. Nie stwierdzono tam obecności gatunku

Tabela 1. Poziom spasożytowania gąsienic motyli na plantacjach borówki wysokiej w latach 2003-2006

Table 1. Parasitization level of lepidopteran caterpillars sampled in highbush blueberry plantations in 2003-2006

\begin{tabular}{|c|c|c|c|c|c|c|}
\hline \multirow{3}{*}{$\begin{array}{l}\text { Lata badań } \\
\text { Years of study }\end{array}$} & \multicolumn{6}{|c|}{ Plantacja-Plantation } \\
\hline & \multicolumn{2}{|c|}{ Palikije } & \multicolumn{2}{|c|}{ Niemce } & \multicolumn{2}{|c|}{ Osmolice } \\
\hline & $\mathrm{nr}$ - No. & {$[\%]$} & $\mathrm{nr}-$ No. & {$[\%]$} & $\mathrm{nr}-$ No. & {$[\%]$} \\
\hline 2003 & 557 & 10,23 & 256 & 5,08 & 88 & 0 \\
\hline 2004 & 117 & 0,85 & 219 & 1,37 & 71 & 4,23 \\
\hline 2005 & 31 & 9,68 & 29 & 17,24 & 21 & 0 \\
\hline 2006 & 100 & 7,0 & 18 & 0 & 40 & 22,5 \\
\hline Ogółem - Total & 805 & 8,44 & 522 & 4,02 & 220 & 5,45 \\
\hline
\end{tabular}




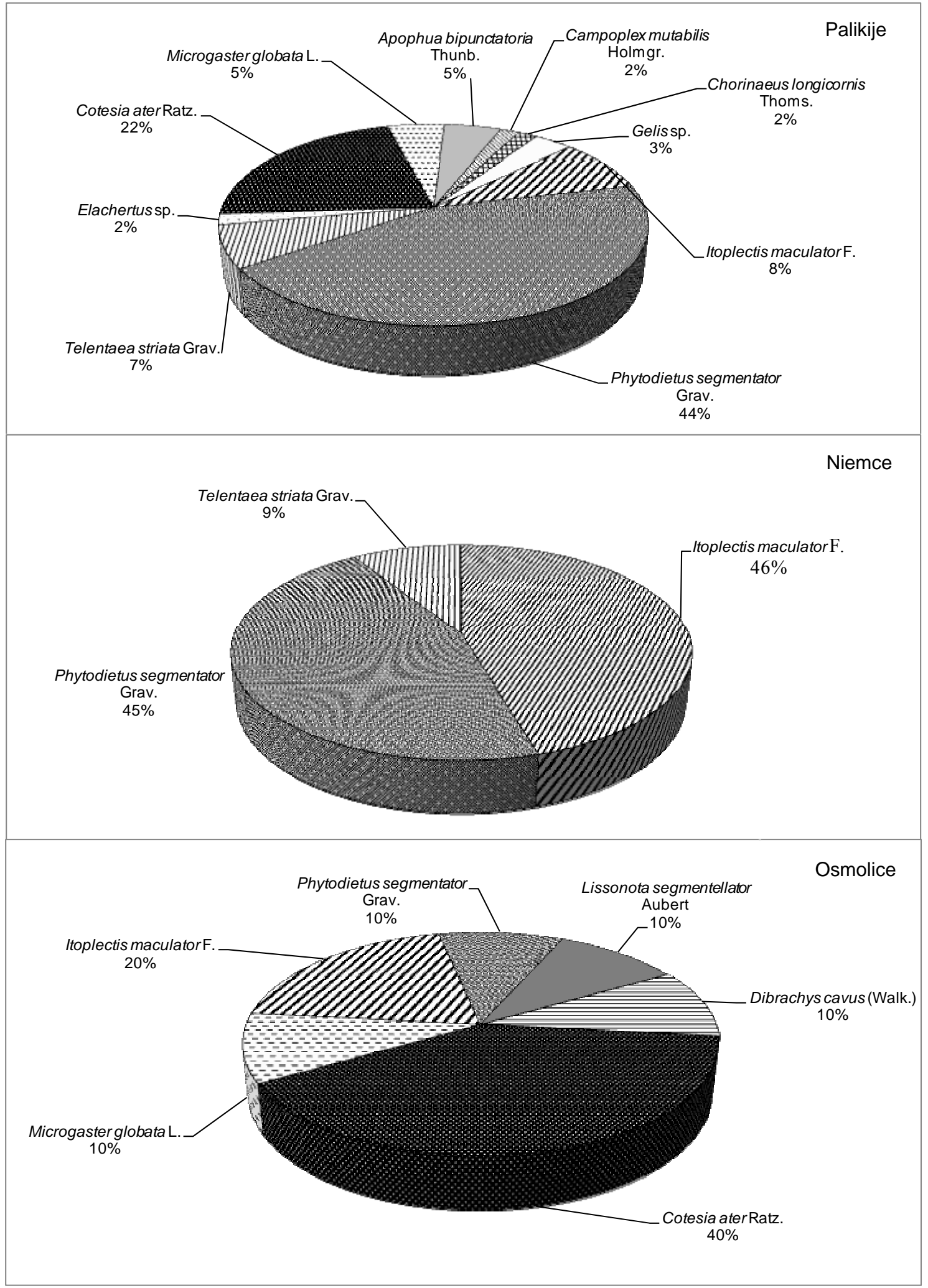

Rys. 1. Procentowy udział gatunków błonkówek pasożytniczych wyhodowanych z gąsienic motyli zebranych na plantacjach borówki wysokiej w latach 2003-2006

Fig. 1. Percentage of hymenopteran parasitoids reared from lapidopteran caterpillars collected on highbush blueberry plantations in the years 2003-2006

Dibrachys cavus z rodziny Pteromalidae. W Niemcach odnotowano jedynie trzy gatunki należące do rodziny Ichneumonidae, a w Osmolicach sześć gatunków nale- żących do rodzin: Pteromalidae, Braconidae i Ichneumonidae. 
Tabela 2. Skład gatunkowy Hymenoptera-Parasitica wyhodowanych ze stadiów preimaginalnych larw motyli żerujących na krzewach borówki wysokiej w latach 2003-2006

Table 2. Species composition of Hymenoptera-Parasitica reared from preimaginal stages of lepidopteran feeding on highbush blueberry in 2003-2006

\begin{tabular}{|c|c|c|c|}
\hline \multirow{2}{*}{$\begin{array}{c}\text { Rodzina - Gatunek } \\
\text { Family - Species }\end{array}$} & \multicolumn{3}{|c|}{ Plantacja - Plantation } \\
\hline & Palikije & Niemce & Osmolice \\
\hline \multicolumn{4}{|c|}{ Nadrodzina - Superfamily: Chalcidoidea } \\
\hline \multicolumn{4}{|c|}{ Eulophidae } \\
\hline Elachertus sp. & 1 & 0 & 0 \\
\hline \multicolumn{4}{|c|}{ Pteromalidae } \\
\hline Dibrachys cavus (Walk.) & 0 & 0 & 1 \\
\hline \multicolumn{4}{|c|}{ Nadrodzina - Superfamily: Ichneumonoidea } \\
\hline \multicolumn{4}{|c|}{ Braconidae } \\
\hline Cotesia ater Ratz. & 13 & 0 & 4 \\
\hline Microgaster globata L. & 3 & 0 & 1 \\
\hline \multicolumn{4}{|c|}{ Ichneumonidae } \\
\hline Apophua bipunctatoria Thunb. & 3 & 0 & 0 \\
\hline Campoplex mutabilis Holmgr. & 1 & 0 & 0 \\
\hline Chorinaeus longicornis Thoms. & 1 & 0 & 0 \\
\hline Gelis sp. & 2 & 0 & 0 \\
\hline Itoplectis maculator F. & 5 & 5 & 2 \\
\hline Phytodietus segmentator Grav. & 26 & 5 & 1 \\
\hline Telentaea striata Grav. & 4 & 1 & 0 \\
\hline Lissonota segmentellator Aubert & 0 & 0 & 1 \\
\hline Ogółem - Total & 59 & 11 & 10 \\
\hline
\end{tabular}

\section{Wnioski / Conclusions}

1. Liczebność larw motyli i ich spasożytowanie były zróżnicowane w zależności od roku badań i lokalizacji plantacji.
2. Ogółem w okresie badań spasożytowanie gąsienic żerujących na krzewach borówki wysokiej wyniosło $6,85 \%$.

3. Najefektywniejszymi parazytoidami okazały się dwa gatunki należące do rodziny Ichneumonidae: $P$. segmentator i I. maculator oraz jeden reprezentant rodziny Braconidae - C. ater.

\section{Literatura / References}

Janiuk M., Gantner M., Kot I. 2011. Zwójki (Lepidoptera, Tortricidae) żerujące na krzewach borówki wysokiej (Vaccinium corymbosum L.) na plantacjach w okolicy Lublina. [Leafrollers (Lepidoptera, Tortricidae) feeding on blueberry shrubs (Vaccinium corymbosum L.) on plantations in the environs of Lublin]. Prog. Plant Prot./Post. Ochr. Roślin 51 (3): 1114-1118.

Łabanowska B.H., Maciesiak A. 2013. Aktualne problemy w ochronie roślin sadowniczych przed szkodnikami. s. 18-23. W: 56. Ogólnopolska Konf. Rośl. Sadown. „Integrowana ochrona roślin - standardem od 2014 roku”. Skierniewice, 14-15 lutego 2013 , 179 ss.

Miczulski B., Anasiewicz A. 1972. Materiały do znajomości pasożytniczej entomofauny kompleksu motyli zwójkowatych (Tortricidae) występujących na porzeczce czarnej - Ribes nigrum L. i czerwonej - R. rubrum L. oraz na agreście - R. grossularia L. w okolicach Lublina. Pol. Pismo Entomol. 42 (1): 211-222.

Piekarska H. 1989. Ichneumonids (Hymenoptera, Ichneumonidae) parasites of leaf-rollers in apple orchards vaccinity. Rocz. AR Poznań 202: $153-162$.

Piekarska-Boniecka H., Wilkaniec B. 1996. Naturalna regulacja zwójkówek (Lepidoptera, Tortricidae) występujących na porzeczce czarnej w okolicach Poznania. [A natural regulation of the leaf-rollers (Lepidoptera, Tortricidae) occurring on the black currant in the environs of Poznań]. Prog. Plant Prot./Post. Ochr. Roślin 36 (2): 82-84.

Płuciennik Z. 2013. Owocówka jabłkóweczka i zwójkówki liściowe w 2012 roku. s. 90-93. W: 56. Ogólnopolska Konf. Rośl. Sadown. „Integrowana ochrona roślin - standardem od 2014 roku”. Skierniewice, 14-15 lutego 2013, 179 ss.

Płuciennik Z., Olszak R.W. 2010a. Zwalczanie zwójkówek liściowych. s. 93-96. W: 53. Ogólnopolska Konf. Rośl. Sadown. „Ochrona upraw sadowniczych w świetle nowych wymogów UE”. Skierniewice, 25-26 lutego 2010, 196 ss.

Płuciennik Z., Olszak R.W. 2010b. The role of parasitoids in limiting the harmfulness of leaf-rollers in apple orchards. J. Plant Prot. Res. 50 (1): 1-8.

Tian M., Piekarska-Boniecka H. 1998. The effects of ichneumonids (Hymenoptera) and other parasitoids on the rose leafroller, Archips rosanus (L.) (Lepidoptera, Tortricidae), from black currant. Roczn. AR Poznań 26 (301): 79-89. 